\title{
Preparation and structure of alumina supported niobia model catalysts.
}

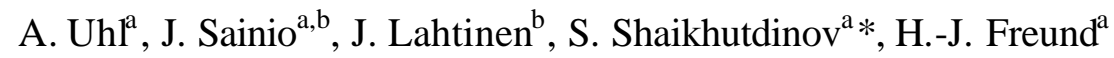 \\ ${ }^{a}$ Fritz Haber Institute of the Max Planck Society, Faradayweg 4-6, 14195 Berlin, Germany \\ ${ }^{b}$ Laboratory of Physics, Helsinki University of Technology, P.O. Box 1100, FIN-02015 HUT, \\ Finland
}

\begin{abstract}
.
Niobia/alumina model catalysts were prepared by physical vapor deposition of $\mathrm{Nb}$ in an oxygen atmosphere onto thin alumina films. Structural characterization, performed with scanning tunneling microscopy and infrared reflection absorption spectroscopy, revealed highly dispersed $\mathrm{N}_{2} \mathrm{O}_{5}$ nanoparticles exposing $\mathrm{Nb}=\mathrm{O}$ groups. Thermal stability of the system was also examined. The results are compared with those obtained on thin niobia films and previously studied vanadia/alumina systems.
\end{abstract}

Keywords: Niobium oxides; Model catalysts; Thin oxide films; Vanadia; Niobia; Scanning tunneling microscopy; Infrared spectroscopy

* Corresponding author: shaikhutdinov@fhi-berlin.mpg.de 


\section{Introduction.}

Niobium oxide based catalysts have received much attention due to their potential use in many industrially important processes such as the Fischer-Tropsch reaction, oxidative coupling of methane, etc. (e.g., see [1-8]). In these catalysts, the niobia is basically used as a support for highly dispersed metal particles and typically forms $\mathrm{Nb}_{2} \mathrm{O}_{5}$ crystallites, which may exist in different polymorphs depending on the heat treatment $[9,10]$. In addition, the niobia can also participate as an active component when added to other high surface area oxides such as alumina and silica, thus forming so called "monolayer" type catalysts based on the structural model where oxide spreads over support [11-15]. The supported niobia catalysts of ten show enhanced catalytic performance as compared to the bulk oxide systems (see e.g. $[2,3,16])$. The atomic structure of the niobia as well as other monolayer catalysts continues to be debated in the literature (see $[5,17,18]$ and references therein).

In order to understand structure-reactivity relationships for niobia based catalysts and elucidate the reaction mechanisms, we have recently begun model studies using well-ordered niobium oxide thin films grown on a metal substrate [19,20]. In continuation of these studies, here we report on the preparation and structure of niobia/alumina model catalysts. Structural characterization was performed with scanning tunneling microscopy (STM) and infrared reflection absorption spectroscopy (IRAS). Thermal stability of these systems was also examined. In addition, we have compared niobia and vanadia model catalysts since niobium and both Group V transition metals, and vanadium are more well-studied in the literature, This may also be helpful in revealing similarities and trends in structure-reactivity relationships for the Group V oxide catalysts.

\section{Experimental.}

The experiments were carried out in two ultra-high vacuum (UHV) chambers (base pressure below $5 \times 10^{-10}$ mbar) denoted as "STM" and "IRAS". Both chambers are equipped with standard facilities for surface cleaning, quadrupole mass-spectrometer (QMS, Hiden) and four-grid low energy electron diffraction (LEED, Specs), also used for Auger electron 
spectroscopy (AES). The IRAS chamber is additionally equipped with high-resolution electron energy loss spectroscopy (HREELS, Delta 0.5, VSI GmbH).

The crystal temperature was controlled using a chromel-alumel thermocouple spotwelded to the edge of the crystal and a feedback control system (Schlichting Phys. Instrum.). In the STM chamber, heating was achieved by electron bombardment from the backside of the crystal using a W filament. For the IRAS studies, the crystal was placed between two parallel Ta wires used for resistive heating. Gases ( $\mathrm{CO}$ and $\mathrm{O}_{2}$, both 5.0 from AGA) were exposed to the samples using a directional gas doser.

The thin alumina films were grown on a $\mathrm{NiAl}(110)$ single crystal as described elsewhere [21-23]. The surface was cleaned by a standard procedure including cycles of $\mathrm{Ar}^{+}$ sputtering and annealing to $1250 \mathrm{~K}$ and checked by AES. Then the surface was exposed to $10^{-6}$ mbar $\mathrm{O}_{2}$ at $550 \mathrm{~K}$ and annealed in $\operatorname{UHV}(5 \mathrm{~min}, 1140 \mathrm{~K}$ ). The oxidation-annealing procedure was repeated in order to form a dense, hole-free alumina film.

Niobium (as well as vanadium) was vapor deposited onto the alumina film in $10^{-7} \mathrm{mbar}$ $\mathrm{O}_{2}$ at $300 \mathrm{~K}$ from a $\mathrm{Nb}(\mathrm{V})$ rod (2 mm diameter, Goodfellow, $\left.99.99 \%\right)$ using a commercial evaporator (Focus EFM3). The deposition rate was calibrated using a quartz microbalance (in the IRAS chamber) or by STM, and was in the range of $0.05 \AA / m i n$. The niobium oxide coverage is presented in the text in amounts of metallic $\mathrm{Nb}$ as a nominal thickness (in $\AA$ ). Approximately $1.6 \AA$ of $\mathrm{Nb}$ corresponds to $\mathrm{Nb}_{2} \mathrm{O}_{5}$ monolayer coverage [19].

Photoelectron spectra were measured on the niobia films using synchrotron radiation at BESSY II (Berlin, beamline UE52-PGM1). The spectra were taken with a Scienta SES200 analyzer. Spectra were recorded with a photon energy of $310 \mathrm{eV}$ for $\mathrm{Nb} 3 \mathrm{~d}$ level. The energy was calibrated via the Fermi edge and also the binding energy of the Au $4 \mathrm{f}$ level $(84.0 \mathrm{eV})$ of a clean gold foil.

The HREEL-spectra on the niobia films were measured in a specular geometry (grazing angle $30^{\circ}$, spectral resolution $\sim 4 \mathrm{meV}$ ) with a primary electron energy $5 \mathrm{eV}$.

The STM images presented here were subjected to plane corrections and low-pass filtering.

\section{Results and discussion.}


Figure 1 shows a series of STM images of the niobia/alumina surface prepared at room temperature at increasing niobia coverage. At $0.1 \AA$ coverage, the particles are randomly dispersed on the surface, i.e. both on and between the line defects (antiphase and reflection domain boundaries, steps) clearly visible in Fig. 1a. As previously shown for other metal deposits on the alumina film, the particle spatial distribution basically reflects the degree of metal support interaction $[21,22]$. The absence of preferential nucleation for niobia, as shown in Fig. 1, can be interpreted as a relatively strong interaction between $\mathrm{Nb}$ atoms and the alumina surface.

Particle density increases with the coverage up to $\sim 1 \AA$ and then saturates at $\sim 2 \times 10^{13}$ $\mathrm{cm}^{-2}$, while the average particle height is nearly constant from the onset (see Fig. 1f). Note that at high coverage the particle size is difficult to determine precisely due to the tip deconvolution effect. Obviously, niobia grows in a three-dimensional mode under these conditions.

Infrared spectroscopy was used to study the surface structure of the alumina-supported niobia particles. The IRAS method allows one to investigate phonon vibrations at oxide surfaces as well as of adsorbates such as $\mathrm{CO}$ used here as a probe molecule. The phonon region of the IRA-spectra is shown in Fig. 2a. The pristine alumina film exhibits a sharp peak at $\sim 865 \mathrm{~cm}^{-1}$ as previously reported [23]. The alumina phonon attenuates upon niobia deposition and a new band appears as a shoulder at around $900 \mathrm{~cm}^{-1}$, ultimately resulting in a broad signal centered at $885 \mathrm{~cm}^{-1}$ for the highest niobia coverage studied. The spectral broadening is consistent with the formation of randomly dispersed small niobia particles as revealed by STM. At the coverage of $1 \AA$, a band centered at $986 \mathrm{~cm}^{-1}$ emerges which grows in intensity with the coverage.

The assignment of these spectral features is facilitated by comparison with the results on a supported vanadia system previously studied in detail $[17,24,25]$. For convenience, the bottom curve in Fig. $2 \mathrm{a}$ shows the spectrum obtained for the similarly prepared $3.5 \AA$ vanadia/aluimina sample in the same experimental setup. Based on Raman and IR spectroscopy results, the peak at $1045 \mathrm{~cm}^{-1}$ has been assigned to the stretching of vanadyl $(\mathrm{V}=\mathrm{O})$ groups. Meanwhile the broad signal at $\sim 950 \mathrm{~cm}^{-1}$ is associated with vibrations involving $\mathrm{V}-\mathrm{O}-\mathrm{Al}$ linkage at the vanadia/alumina interface as predicted by heoretical calculations $[17,24]$. Therefore, turning back to the niobia/alumina system, the peak at 986 
$\mathrm{cm}^{-1}$ must be assigned to the niobyl $(\mathrm{Nb}=\mathrm{O})$ stretching, and the signal at $890 \mathrm{~cm}^{-1}$ must be assigned to $\mathrm{Nb}-\mathrm{O}-\mathrm{Al}$ interface vibrations, which should show lower frequencies as compared to vanadia/alumina, based solely on mass considerations ( $\mathrm{Nb}$ atom is heavier than $\mathrm{V}$ ).

This conclusion is further supported by HREELS and PES studies of the thin niobia films grown on a $\mathrm{Cu}_{3} \mathrm{Au}(100)$ substrate (see Fig. 3). The PE-spectra for the well-ordered monolayer films [19] showed the binding energy (BE) of the $\mathrm{Nb} 3 \mathrm{~d}_{5 / 2}$ core level to be 206.4 $\mathrm{eV}$, which is a bit lower than observed for $\mathrm{Nb}_{2} \mathrm{O}_{5}[26,27]$ due to the well-known screening effect of the metal substrate underneath. According to the structure of the monolayer film proposed [6], it contains the outmost oxygen ions in the bridge position forming the $\mathrm{Nb}-\mathrm{O}$ $\mathrm{Nb}$ bonds. As a result, HREEL-spectra only showed the signal at $703 \mathrm{~cm}^{-1}$, i.e. typical for stretching and/or bending vibrations of the $\mathrm{Nb}-\mathrm{O}-\mathrm{Nb}$ linkage [28].

Thicker niobia films, prepared on the same substrate by repeated cycles of $\mathrm{Nb}$ deposition and annealing at $900 \mathrm{~K}$ in $10^{-6} \mathrm{mbar}_{2}$, are less ordered than the monolayer films as judged by LEED and STM. The PES measurements revealed the signal at $207.4 \mathrm{eV}$ for the $\mathrm{Nb}_{3} \mathrm{~d}_{5 / 2}$ level (see Fig.3) clearly showing that the multilayer niobia films consist of $\mathrm{Nb}$ cations in the highest oxidation state, 5+. Concomitantly, the small shoulder at $206.4 \mathrm{eV}$, observed at normal electron emission and not in grazing emission, can be assigned to $\mathrm{Nb}$ ions at the niobia/substrate interface.

In contrast to the monolayer films, the multilayer niobia films showed energy losses at 565,842 and $984 \mathrm{~cm}^{-1}$. To the best of our knowledge, only Xie et al. [29] reported on vibrational properties of the niobia films. The authors prepared different thin films $\left(\mathrm{NbO}_{\mathrm{x}}\right.$ and $\mathrm{Nb}_{2} \mathrm{O}_{5}$ in their notation) on $\mathrm{Pt}(111)$, which turned out to be of a poor crystallinity. These films showed signals at 384 and $926 \mathrm{~cm}^{-1}$ in HREEL-spectra. (Note the limited resolution of the spectra reported in [29]: $\sim 96 \mathrm{~cm}^{-1}$ vs $\sim 50 \mathrm{~cm}^{-1}$ in our work.) The authors assigned the high frequency band to the stretching vibrations of $\mathrm{Nb}=\mathrm{O}$ species, although the frequency is significantly lower than any observed on $\mathrm{H}_{-} \mathrm{Nb}_{2} \mathrm{O}_{5}$ but much higher than that of other stable crystalline (T- and TT-) or amorphous phases of niobium pentoxide $\left(700-870 \mathrm{~cm}^{-1}\right)$ by Raman and IR spectroscopy [30-32]. Note also for comparison that the $\mathrm{NbO}_{2}$ phase showed transverse optical phonons below $\sim 700 \mathrm{~cm}^{-1}$ [33], which would correspond to surface phonon frequencies of $807 \mathrm{~cm}^{-1}$ as calculated in [29]. 
Based on the spectral characteristics of reference $\mathrm{Nb}$ compounds, Jehng and Wachs [32] proposed a correlation between the stretching frequencies of $\mathrm{Nb}-\mathrm{O}$ surface sites and the extent of distortion of $\mathrm{NbO}_{6}$ octahedra, which compose most of the niobium oxide compounds via edge and corner sharing. These authors suggested that highly and slightly distorted structures exhibit vibrations in the regions of $850-1000 \mathrm{~cm}^{-1}$ and $500-700 \mathrm{~cm}^{-1}$, respectively. It should be mentioned however that, due to the existence of many often coexisting metastable polymorphs of $\mathrm{Nb}_{2} \mathrm{O}_{5}$, the precise peak position may critically depend on the sample preparation. Note also that IRA- and HREEL-spectroscopy of the thin films grown on refractory metal substrates follow the selection rules, whereby only vibrations resulting in a dynamic dipole moment perpendicular to the metal surface will be detected. Therefore, some vibrational bands in IR (and Raman) spectra on powders may be inactive in the IRAS measurements of the thin films and supported nanoparticles, thus making the comparison rather uncertain. However, it is clear that the bands above $900 \mathrm{~cm}^{-1}$ must be associated with the surface $\mathrm{Nb}=\mathrm{O}$ species present in $\mathrm{Nb}_{2} \mathrm{O}_{5}$.

The position of the high frequency band at $\sim 984 \mathrm{~cm}^{-1}$ in HREEL-spectra shown in Fig. 3 almost coincides with that observed on the supported niobia particles $\left(\sim 986 \mathrm{~cm}^{-1}\right.$, see Fig. 2) and therefore can be assigned to $\mathrm{Nb}=\mathrm{O}$ species. The comparative study strongly suggests that both three dimensional $\mathrm{Nb}$ particles on the alumina films and multilayer niobia films prepared under low oxygen pressure conditions $\left(\sim 10^{-6} \mathrm{mbar}\right)$ are in fully oxidized, niobium (5+) oxide phase exposing $\mathrm{Nb}=\mathrm{O}$ species on the surface, i.e. like in $\mathrm{H}_{-}-\mathrm{Nb}_{2} \mathrm{O}_{5}$. To some extent, these results are in contrast with those previously observed for vanadia model systems (both the supported vanadia and the vanadia films) where vanadium deposition under the same oxygen pressure conditions $\left(\sim 10^{-6}\right.$ mbar) leads to the formation of $\mathrm{V}_{2} \mathrm{O}_{3}$ particles and films, both $\mathrm{V}=\mathrm{O}$ terminated. This difference can be explained by the fact that niobium, in contrast to vanadium, does not form a stable sesquioxide and therefore transforms into the $\mathrm{Nb}_{2} \mathrm{O}_{5}$ phase.

An IRAS study of adsorption of $\mathrm{CO}$ as a probe molecule further supports the conclusion on the oxidation state of $\mathrm{Nb}$ in the model systems. Interaction of $\mathrm{CO}$ with niobia is found to be weak and can be seen only at low temperatures (see Fig. 2b). The strongly blue-shifted frequency of $\mathrm{CO}$ as compared to the gas phase (2191 vs $2143 \mathrm{~cm}^{-1}$ ) implies that $\mathrm{CO}$ is linearly adsorbed on top of $\mathrm{Nb}^{5+}$ sites $[20,34]$. A similar feature at $2190 \mathrm{~cm}^{-1}$ was 
also obtained on the thin niobia films (not shown here), i.e. fully consistent with the above PES results.

Therefore, combined STM and IRAS studies show that niobia deposited on thin alumina films in an oxygen atmosphere form small $\mathrm{Nb}_{2} \mathrm{O}_{5}$ particles terminated by the $\mathrm{Nb}=\mathrm{O}$ groups and also $\mathrm{Nb}^{5+}$ sites.

Thermal stability of the supported niobia particles was further examined by STM and IRAS. Figure 4 shows STM images of the $0.5 \AA$ niobia/alumina sample after a thermal flash to elevated temperatures $(500-900 \mathrm{~K})$ in UHV. Annealing to $700 \mathrm{~K}$ basically decreases the particle density partially due to sintering of the particles (some particles gain in size) and also due to niobia migration into the film, which is more clearly observed after annealing to 900 K. As previously shown for other metal particles [22], the interdiffusion probably goes through the line defects of the alumina film, thus resulting in their decoration (see Fig. 4d).

The $2.5 \AA$ niobia/alumina sample, shown in Fig. 5a, was first flashed in UHV to $700 \mathrm{~K}$, then oxidized in $10^{-7}$ mbar $\mathrm{O}_{2}$ at $400 \mathrm{~K}$ and finally at $900 \mathrm{~K}$. One can see that, in contrast to annealing in UHV, ambient oxygen precludes the migration of the niobia particles, and only partial sintering occurs at $900 \mathrm{~K}$.

Fig. 6 shows the results of a complementary IRAS study for $2.5 \AA$ niobia/alumina sample. Initially existing $\mathrm{Nb}=\mathrm{O}$ species at $\sim 983 \mathrm{~cm}^{-1}$ apparently disappear upon heating to $700 \mathrm{~K}$. Concomitantly, the broad band centered at $\sim 900 \mathrm{~cm}^{-1}$ and assigned to the $\mathrm{Nb}-\mathrm{O}-\mathrm{Al}$ interface vibrations, becomes sharper most probably due to a strong attenuation of the band at $865 \mathrm{~cm}^{-1}$ corresponding to the pristine alumina film. This effect can be explained by the onset of niobia migration as revealed by STM and discussed above. Mild oxidation at $400 \mathrm{~K}$ recovers the niobyl species without affecting the interface region. However, further oxida tion at $900 \mathrm{~K}$ shifts the interface phonon from $915 \mathrm{~cm}^{-1}$ to $948 \mathrm{~cm}^{-1}$ (partially overlapping with the $\mathrm{Nb}=\mathrm{O}$ band). This shift can be related to the structural transformations of the niobia/alumina interface since the STM results showed that overall particle morphology is not affected much by oxidation at $900 \mathrm{~K}$. Note also that this finding indirectly supports our previous assignment of the $\sim 900 \mathrm{~cm}^{-1}$ band to niobia/alumina interface phonon.

The effect of ambient oxygen on the thermal stability of the niobia particles can be rationalized in terms of oxygen preventing the reduction of the niobia surface and hence migration of the $\mathrm{Nb}$ atoms into the film. In addition, previous studies on the oxygen 
interaction with alumina supported particles showed that the metal prticles may promote thickening of the alumina film via oxygen dissociation and subsequent diffusion of atomic oxygen to the alumina/NiAl interface $[35,36]$. This in turn may also alter the interaction of the niobia particles and the alumina film.

\section{Summary}

Niobia/alumina model catalysts were prepared by physical vapor deposition of $\mathrm{Nb}$ in an oxygen atmosphere ( 10 $\left.10^{-7} \mathrm{mbar}, 300 \mathrm{~K}\right)$ onto thin well-ordered alumina films grown on $\mathrm{NiAl}(110)$. Using scanning tunneling microscopy and infrared reflection absorption spectroscopy as well as $\mathrm{CO}$ as a probe molecule, we have found that niobia forms randomly dispersed $\mathrm{N}_{2} \mathrm{O}_{5}$ nanoparticles exposing $\mathrm{Nb}=\mathrm{O}$ and $\mathrm{Nb}^{5+}$ surface sites. The model catalysts are fairly stable up to $\sim 700 \mathrm{~K}$ in vacuum and much more stable in ambient oxyge $\mathrm{n}$. The structural characteristics of niobia/alumina are similar to the previously studied vanadia/alumina system, except that vanadium (3+) forms a sesquioxide but fully oxidized niobium (5+) pentoxide phases are formed. Both systems primarily exhibit metal-oxygen double bond surface terminations $(\mathrm{Nb}=\mathrm{O}$ and $\mathrm{V}=\mathrm{O})$.

\section{Acknowledgements}

We thank H. Kuhlenbeck, S. Guimond and D. Starr for the PES data on the niobia films. J.S. thanks the Academy of Finland for funding. The work is supported by Deutsche Forschungs gemeinschaft through the SFB 546. 


\section{References}

[1] J.-M. Jehng, I.E. Wachs, Catal. Today 8 (1990), 37.

[2] I. Nowak, M. Ziolek, Chem. Rev. 99 (1999), 3603.

[3] M. Ziolek, Catal. Today, 78 (2003) 47.

[4] K. Tanabe, Catal. Today 78 (2003), 65.

[5] I.E. Wachs, Catal. Today 100 (2005), 79.

[6] F.B. Noronha, D.A.G. Aranda, A.P. Ordine, M. Schmal, Catal. Today, 57 (2000), 275.

[7] M. Schmal, D.A.G. Aranda, R. R. Soares, F.B.Noronha and A. Frydman, Catal. Today, 57 (2000) 169.

[8] F.M.T. Mendes, F.B. Noronha, M. Schmal, Stud. Surf. Sci. Catal. 130 (2001), 3717.

[9] H. Schafer, R. Gruehn, F. Schulte, Angew. Chem. Int. Ed. 5 (1966), 40.

[10] F. Izumi, H. Kodama, Z. Anorg. Allg. Chem. 440 (1978), 155.

[11] M. Nischimura, K. Asakura, Y. Iwasawa, J. Chem. Soc. Chem. Commun., 1986, 1660.

[12] F. Roozeboom, M.C. Mettelmeijer-Hazeleger, J.A.Moulijn, J. Medema, V.H.J. de Beer, R.J. Gellings, J. Phys. Chem. 84 (1980) 2783.

[13] G. Mestl, T.K.K. Srinivasan, Catal. Rev.-Sci. Eng., 40 (1998), 451.

[14] I.E. Wachs, B.M. Weckhuysen, Appl. Cat. A 157 (1997), 67.

[15] I.E. Wachs, Catal. Today, 27 (1996), 437.

[16] J.-M. Jehng, I.E. Wachs, Catal. Today 16 (1993), 417.

[17] N. Magg, B. Immaraporn, J. B. Giorgi, T. Schroeder, J. Döbler, Z. Wu, E. Kondratenko, M. Cherian, M. Baerns, P. C. Stair, M. Bäumer, J. Sauer, H.-J. Freund, J. Catal. 226 (2004), 88.

[18] J.N.J. van Lingen, O.L.J. Gijzeman, B.M. Weckhuysen, J.H. van Lenthe, J. Catal. 239 (2006), 34.

[19] D.E. Starr, F.M.T. Mendes, J. Middeke, R.-P. Blum, H. Niehus, D. Lahav, S. Guimond, A. Uhl, T. Klüner, M. Schmal, H. Kuhlenbeck, S. Shaikhutdinov, H.-J. Freund, Surf. Sci. 599 (2005), 14.

[20] F.M.T. Mendes, A. Uhl, D.E. Starr, S. Guimond, M. Schmal, H. Kuhlenbeck, S. Shaikhutdinov, H.-J. Freund, Catal. Lett. 111 (2006), 35.

[21] M. Bäumer, H.-J. Freund, Prog. Surf. Sci. 61 (1999), 127.

[22] M. Heemeier, S. Stempel, S. Shaikhutdinov, J. Libuda, M. Bäumer, R.J. Oldman, S.D. Jackson, H.-J. Freund, Surf. Sci. 523 (2003), 103.

[23] M. Frank, K. Wolter, N. Magg, M. Heemeier, R. Kühnemuth, M. Bäumer, H.-J. Freund, Surf. Sci. 492 (2001), 270.

[24] N. Magg, J. B. Giorgi, T. Schröder, M. Bäumer, H.-J. Freund, J. Phys. Chem. B 106 (2002), 8756.

[25] N. Magg, J. B. Giorgi, A. Hammoudeh, T. Schröder, M. Bäumer, H.-J. Freund, J. Phys. Chem. B 107 (2003), 9003.

[26] J. Halbritter, Appl. Phys. A 43 (1987), 1.

[27] M.M. Thiam, Z. Bastl, Surf. Sci., 507-510 (2002), 678.

[28] A.A. McConnell, J.S. Anderson, C.N.R. Rao, Spectrochim. Acta 32A (1976), 1067.

[29] L. Xie, D. Wang, C. Zhong, X. Guo, T. Ushikubo, K. Wada, Surf. Sci. 320 (1994), 62.

[30] R.M. Pittman, A.T. Bell, J. Phys. Chem., 97 (1993), 12178. 
[31] T. Ikeya, M. Senna, J. Non-Cryst. Sol., 105 (1988), 243.

[32] J.-M. Jehng, I.E. Wachs, Chem Mater., 3 (1991), 100.

[33] F. Gervais, Phys. Rev. B 23 (1981), 6580.

[34] T. Beutel, V. Siborov, B. Tesche, H. Knözinger, J. Catal. 167 (1997), 379.

[35] S. Shaikhutdinov, M. Heemeier, J. Hoffmann et al. Surf. Sci., 501 (2002), 270.

[36] M. Bäumer, J. Biener, R.J. Madix, Surf. Sci. 432 (1999), 189. 


\section{Figure captions.}
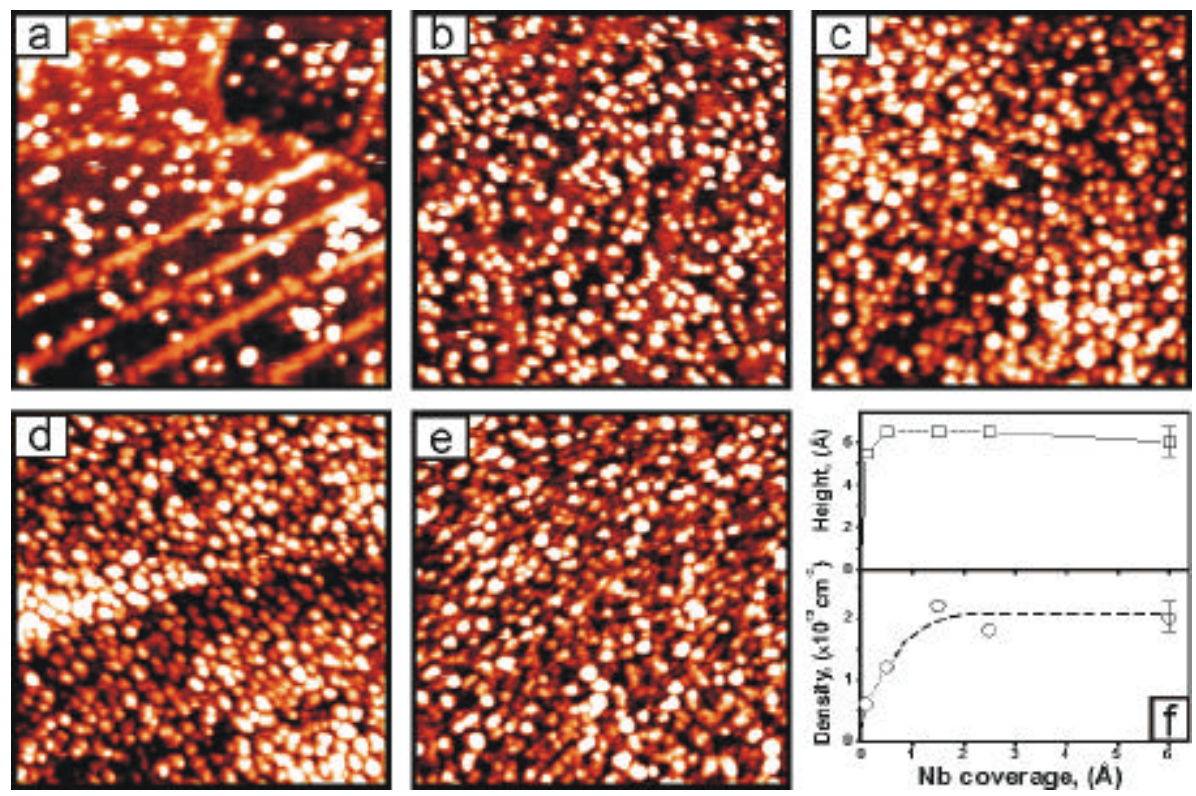

Figure 1. STM images (size $60 \times 60 \mathrm{~nm}^{2}$, tunneling parameters $V_{S}=3 \mathrm{~V}, I=0.1 \mathrm{nA}$ ) of niobia deposited on alumina films at different coverages: (a) $0.1 \AA$; (b) $0.5 \AA$; (c) $1.5 \AA$; (d) $2.5 \AA$; (e) 6.0 Å. (f) Apparent height of niobia particles and particle density as a function of niobia coverage. 

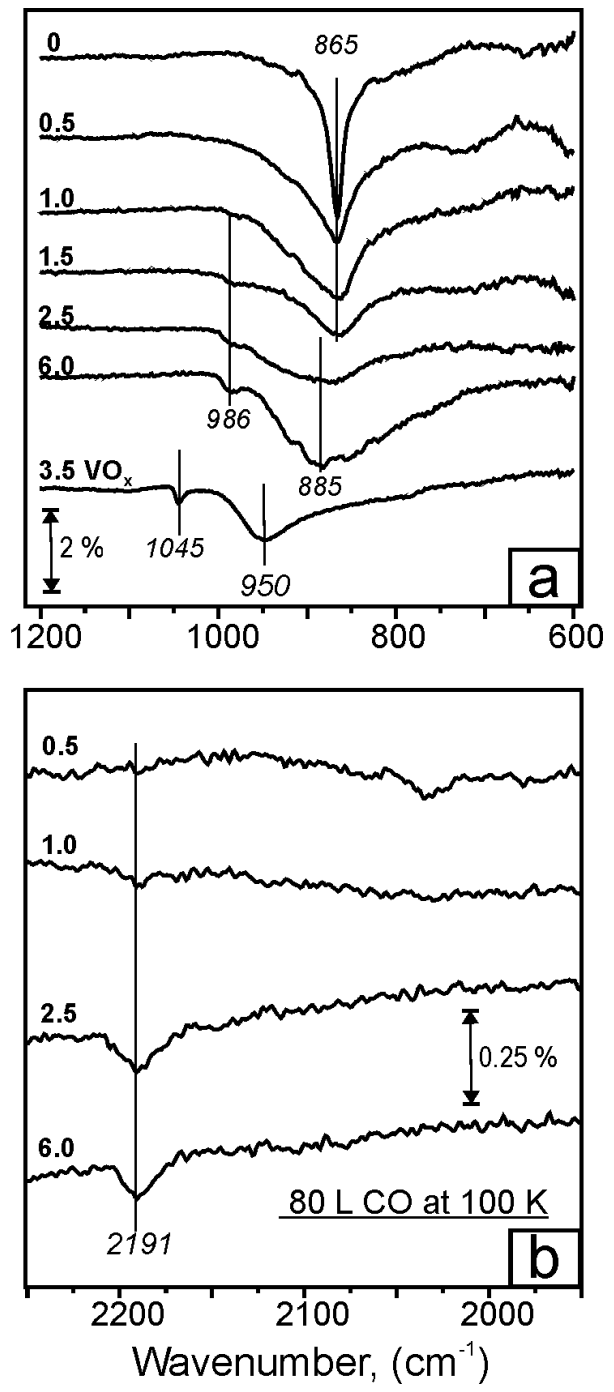

Figure 2. (a) The phonon region of IRA-spectra of the niobia/alumina samples as a function of niobia coverage as indicated (in $\AA$ ). A spectrum for similarly prepared vanadia/alumina is also shown, for comparison. (b) IRA-spectra of $80 \mathrm{~L} \mathrm{CO}$ adsorbed at $100 \mathrm{~K}$ as a function of niobia coverage. All spectra are offset for clarity. 


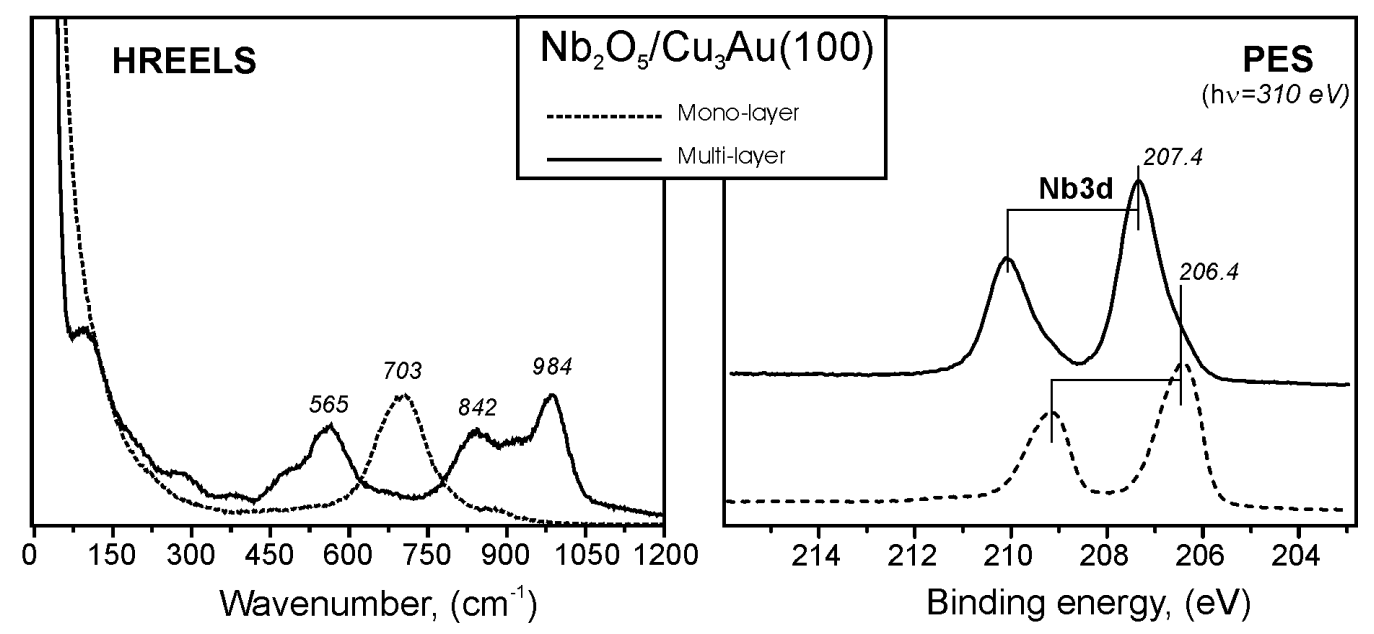

Figure 3. HREEL-spectra measured in specular geometry, and PES spectra measured at normal electron emission for monolayer and multilayer niobia films grown on $\mathrm{Cu}_{3} \mathrm{Au}(100)$ (see the text).
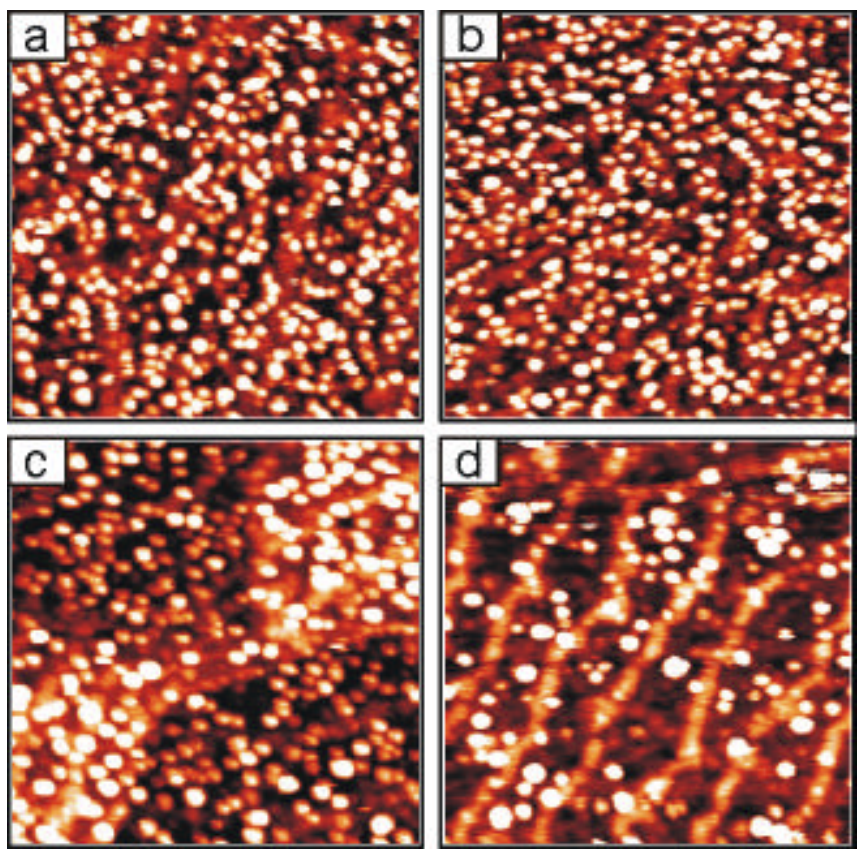

Figure 4. STM images (size $60 \times 60 \mathrm{~nm}^{2}, \mathrm{~V}_{\mathrm{S}}=3 \mathrm{~V}, \mathrm{I}=0.1 \mathrm{nA}$ ) of $0.5 \AA$ niobia/alumina samples: (a) as-prepared at $300 \mathrm{~K}$; (b)-(d) flashed to 500, 700 and $900 \mathrm{~K}$, respectively. Antiphase domain boundaries are clearly seen in (d) due to migration of the niobia deposits through the line defects and their decoration. 

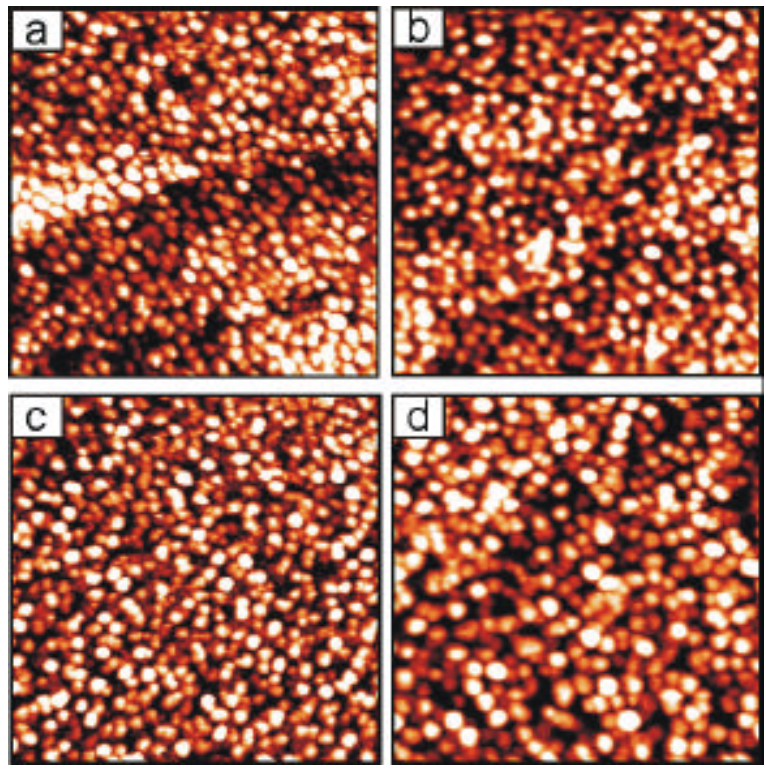

Figure 5. STM images (size $60 \times 60 \mathrm{~nm}^{2}, \mathrm{~V}_{\mathrm{S}}=3 \mathrm{~V}, \mathrm{I}=0.1 \mathrm{nA}$ ) of $2.5 \AA$ niobia sample: (a) as prepared at $300 \mathrm{~K}$; (b) flashed to $700 \mathrm{~K}$ in UHV; (c,d) flashed to $400 \mathrm{~K}$ (c) and then to 900 $\mathrm{K}$ (d) in $10^{-7}$ mbar $\mathrm{O}_{2}$. Note smaller morphological changes for the oxidized samples as compared to the UHV annealed samples (see Fig.4).

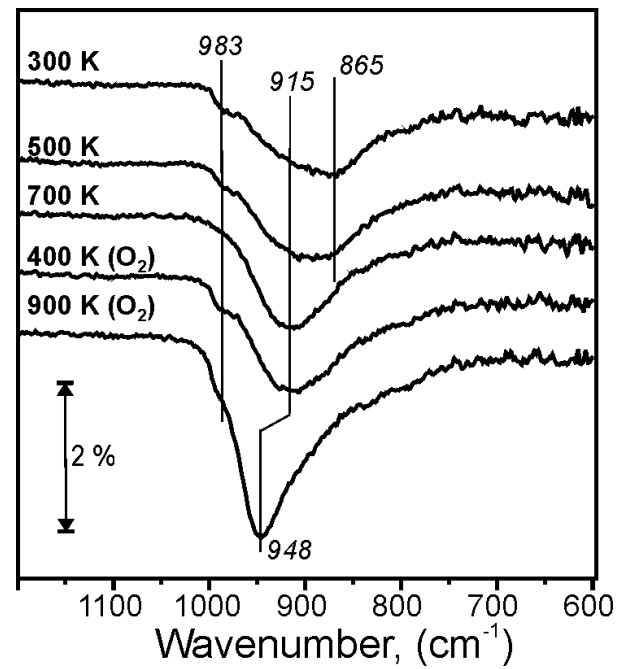

Figure 6. IRA-spectra of $2.5 \AA$ niobia sample annealed to the indicated temperature and subsequently oxidized in $10^{-7}$ mbar of $\mathrm{O}_{2}$ at $400 \mathrm{~K}$ and then at $900 \mathrm{~K}$. The $\mathrm{Nb}=\mathrm{O}$ band at 983 $\mathrm{cm}^{-1}$ disappeared at $700 \mathrm{~K}$ and is recovered upon oxidation treatment. All measurements were performed at room temperature. The spectra are offset for clarity. 